\title{
The value of screening blood donors for antibody to hepatitis B core antigen
}

\author{
AC ARCHER, BJ COHEN, PP MORTIMER \\ From the South West Regional Blood Transfusion Centre, Southmead Road, Bristol BS10 5ND, and the \\ PHLS Virus Reference Laboratory, Central Public Health Laboratory, Colindale Avenue, London NW9 \\ $5 H T$
}

SUMMARY Rapid counter-immunoelectrophoresis (CIE) and radioimmunoassay (RIA) methods for detecting antibody to hepatitis $\mathrm{B}$ core antigen (anti-HBc) were used to screen nearly 8000 blood donors, including 919 prisoners. The prevalence of anti-HBc in prisoner donors (3.4\%) was significantly higher than that in other donors $(0.7 \%)$. The three $\mathrm{HBsAg}$ positive donors in the series were all anti-HBc positive and, of the other 73 anti-HBc positive donors, 62 had antibody to $\mathrm{HBsAg}$ (anti-HBs).

Two panels of control sera, including $155 \mathrm{HBsAg}$ positive samples, were tested by CIE for anti-HBc: 149 of the 155 were anti-HBc positive. Of the six negative samples, four were $\mathrm{HBsAg}$ positive only by RIA. One of the panels, containing 16 weakly $\mathrm{HBsAg}$ positive samples, was available for anti-HBc testing by RIA. Fifteen of the samples were positive and the other was slightly reactive. Donor sera that gave unconfirmable reactions in initial CIE tests were invariably negative when tested by RIA. The RIA was a more sensitive and specific test for anti-HBc than CIE.

The ways in which anti-HBc screening could meet the needs of blood transfusion centres are discussed. We suggest that, in areas of low prevalence, it has a role as a rapid confirmatory test of HBV infection and as a means of identifying those potentially infectious donations in which HBsAg cannot be detected.

Antibody to hepatitis B core antigen (anti-HBc) is a sensitive indicator of hepatitis B virus (HBV) infection. ${ }^{1}$ It develops soon after the surface antigen of hepatitis B (HBsAg) appears and persists, without interruption, through the phases of HBsAg loss and anti-HBs development. Some anti-HBc positive blood donations are infectious, and there have been several reports of post-transfusion hepatitis $B$ due to HBsAg negative but anti-HBc positive blood. ${ }^{2-4}$ The extent of this risk from "anti-HBc only" positive blood is unclear.

Blood donations have not routinely been screened for anti-HBc in spite of the potential infectivity of anti-HBc positive blood. There have been several reasons for this. The antigen has been scarce, lack of funds has precluded an extra screening procedure, and it has been assumed that few anti-HBc positive donations that contain undetectable levels of HBsAg will be identified. Also, it has been shown that, in areas of high HBV prevalence, many transfusable donations will be rejected as a result of

Accepted for publication 23 February 1983
anti-HBc screening unless there is additional testing for anti-HBs. ${ }^{5}$

To assess the value of screening tests for anti-HBc in an area of low prevalence, the occurrence of the antibody in donors in South-West England was investigated. Initially a counter-immunoelectrophoresis (CIE) method was used both for screening and to compare the sensitivity of the anti-HBc test with that of RPHA for HBsAg in detecting potential HBV infectivity in panels of control sera. Subsequently, the introduction of solid phase immunoassay for anti-HBc prompted an extension of the study. A competitive radioimmunoassay (RIA) with a short incubation time (one hour) and a microtitre format compatible with blood transfusion laboratory practice was adopted. This rapid RIA for anti-HBc was used to screen additional donors and to re-examine control sera.

\section{Material and methods}

COUNTER IMMUNOELECTROPHORESIS

From June to October 1979 blood donations 


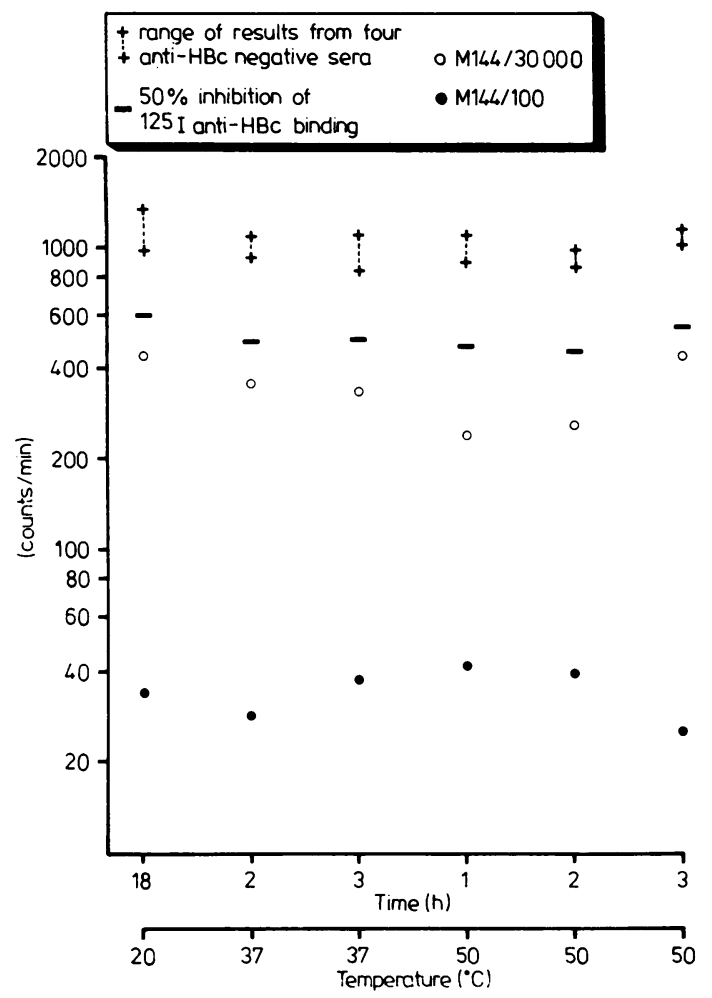

Radioimmunoassay for anti-HBc: effect of varying incubation time and temperature.

received at the South Western Regional Transfusion Centre were routinely screened for anti-HBc by $\mathrm{CIE}^{6}$ and for $\mathrm{HBsAg}$ by a modified commercial reverse passive haemagglutination assay (RPHA). ${ }^{7}$ A total of 5392 donors was tested, including 919 prisoners. All were "new" donors-that is, not previously tested at the Transfusion Centre. Samples of donations found to be positive were sent to the Virus Reference Laboratory for confirmatory tests. These consisted of CIE for anti-HBc using HBcAg purified by isopycnic banding in caesium chloride, and RIA for HBsAg and anti-HBs (Ausria II, Ausab, Abbott Laboratories).

Testing for anti-HBc by CIE was also carried out on two panels of hepatitis B sera intended for proficiency testing. The first was a Blood Transfusion Service (BTS) panel of $139 \mathrm{HBsAg}$ positive samples which included 17 low titred samples provided by the West Scotland Transfusion Service and six low titred samples provided by the North London Blood Transfusion Centre. The second was the "Special Panel" for hepatitis B testing, containing only low titred HBsAg samples, and issued by the Public Health Laboratory Service (PHLS) Division for Microbiological Reagents and Quality Control. The special panel was also examined by RIA (see below).

\section{RADIOIMMUNOASSAY}

A competitive RIA method ${ }^{8}$ was adapted to "Removawell" microtitre plates (Dynatech Laboratories Ltd). A mixture of $15 \mu$ l test sample and $85 \mu l{ }^{125}$ I-labelled anti-HBc IgG was added to the solid phase which was coated with an optimal amount of $\mathrm{HBcAg}$. The effect of various incubation times and temperatures was assessed by testing duplicate samples of strongly anti-HBc positive (M144 diluted 1/100) and weakly anti-HBc positive (M144 diluted 1/30 000) serum, and four anti-HBc negative sera. Though brief incubation at raised temperatures gave less ${ }^{125} \mathrm{I}$-anti-HBc binding than overnight incubation at room temperature, this did not impair detection even of low concentrations of anti-HBc (Figure). Subsequent tests were therefore incubated for one hour at $50^{\circ} \mathrm{C}$. Inhibition of ${ }^{125} \mathrm{I}$-anti-HBc binding by $>50 \%$ was regarded as a positive reaction.

Between August 1981 and February 19822586 donors, including 1210 new ones, were tested for anti-HBc by RIA and for HBsAg by the recently introduced Blood Products Laboratories (BPL) RIA. ${ }^{9}$ As before, positive samples were sent to the Virus Reference Laboratory for confirmatory RIA tests for anti-HBc ${ }^{8}$ and anti-HBs (Ausab).

\section{Results}

COUNTER-IMMUNOELECTROPHORESIS

In CIE screening, 129 of 5392 blood donors were anti-HBc positive. Sixty-one of these reactions were

Table 1 Prevalence of anti-HBc in blood donors measured (i) by CIE and (ii) by RIA

\begin{tabular}{|c|c|c|c|c|c|}
\hline & & \multicolumn{2}{|c|}{ Donors } & \multirow[t]{2}{*}{ Prisoner donors } & \multirow[t]{2}{*}{ Total } \\
\hline & & New & Known & & \\
\hline $\begin{array}{l}\text { CIE } \\
\text { RIA }\end{array}$ & $\begin{array}{l}\text { Number tested } \\
\text { Confirmed positive } \\
\text { Number tested } \\
\text { Confirmed positive }\end{array}$ & $\begin{array}{r}4473 \\
30 \\
1210 \\
8\end{array}$ & $\begin{array}{r}\overline{1} \\
1299\end{array}$ & $\begin{array}{r}919 \\
31 \\
77 \\
2\end{array}$ & $\begin{array}{r}5392 \\
61 \\
2586 \\
15\end{array}$ \\
\hline
\end{tabular}


Table $2 \mathrm{HBs} A \mathrm{~g}$ and anti-HBs status of anti-HBc positive donors

\begin{tabular}{|c|c|c|c|c|}
\hline & $n$ & $\begin{array}{l}\text { HBsAg }+ \\
A n t i-H B s\end{array}$ & $\begin{array}{l}\text { HBsAg- } \\
\text { Anti-HBs + }\end{array}$ & $\begin{array}{l}\text { HBsAg-- } \\
\text { Anti-HBs - }\end{array}$ \\
\hline $\begin{array}{l}\text { Anti-HBc + } \\
\text { (CIE) }\end{array}$ & 61 & 3 & 49 & $8\left(1^{*}\right)$ \\
\hline $\begin{array}{c}\text { Anti-HBc }+ \\
\text { (RIA) }\end{array}$ & 15 & 0 & 12 & 3 \\
\hline
\end{tabular}

*Not available for anti-HBs testing.

Table 3 Results of anti-HBctests on the Blood Transfusion Service panel of $\mathrm{HBs} \mathrm{Ag}$ positive specimens

\begin{tabular}{|c|c|c|c|c|}
\hline & \multicolumn{3}{|c|}{$H B s A g$} & \multirow[b]{2}{*}{ Total } \\
\hline & $\begin{array}{l}C I E+ \\
R P H A+ \\
R I A+\end{array}$ & $\begin{array}{l}\text { CIE - } \\
R P H A+ \\
R I A+\end{array}$ & $\begin{array}{l}C I E- \\
R P H A- \\
R I A+\end{array}$ & \\
\hline \multirow{2}{*}{ Anti-HBc } & 96 & 37 & 4 & 137 \\
\hline & 0 & 0 & 2 & 2 \\
\hline
\end{tabular}

confirmed using gradient-purified $\mathrm{HBcAg}$ (Table 1). The prevalence of anti-HBc was significantly higher $(\mathrm{p}<0.001)$ in prisoners $(3.4 \%)$ than in other donors $(0.7 \%)$. Three $(5 \%)$ of the anti-HBc positive, but none of the anti-HBc negative, donations had HBsAg detectable by RPHA. Forty-nine (82\%) of the anti-HBc positive donations were anti-HBs positive. Eight (13\%) were neither HBsAg nor antiHBs positive (Table 2).

One hundred and thirty-seven of the 139 specimens in the BTS panel of HBsAg positive samples

Table 4 Results of tests on the Public Health Laboratory Service 'Special Panel' of sera for hepatitis testing

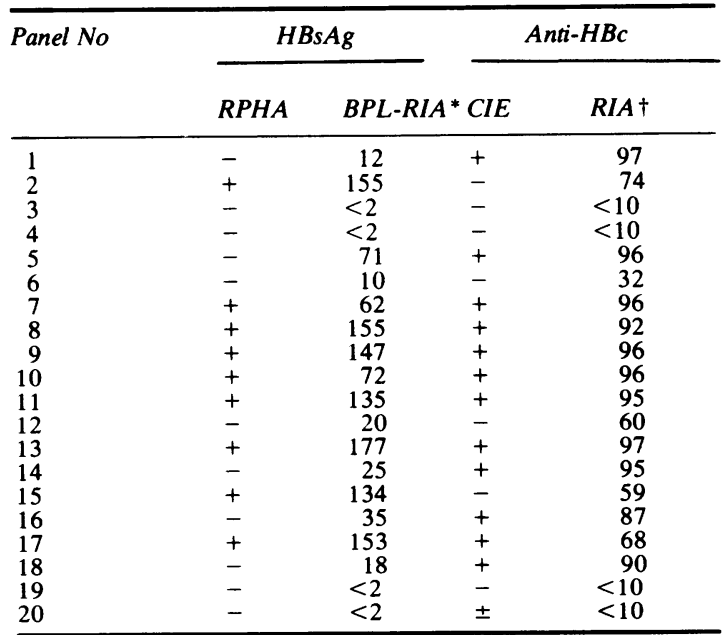

${ }^{*}$ Ratio of test/negative control count.

+ Percentage inhibition of ${ }^{125}$ I-labelled-anti-HBc ( $>50 \%$ binding is considered positive). contained anti-HBc detectable by CIE (Table 3 ). The two anti-HBc negative specimens had low levels of HBsAg. The CIE results on the PHLS special panel were similar (Table 4). Twelve of the 16 HBsAg weakly positive specimens were anti-HBc positive, and four negative. Two of these four specimens were positive for HBsAg by RIA alone.

\section{RADIOIMMUNOASSAY}

Screening of 2586 blood donors yielded 32 anti$\mathrm{HBc}$ positive reactions. Seventeen of these reactions were non-repeatable and negative in confirmatory tests, and $15(0.6 \%)$ were reproducible and could be confirmed (Table 1). Of the new donors $0.7 \%$, and of the known donors $0.4 \%$ had anti-HBc. There were no $\mathrm{HBsAg}$ positive donors in the series. Twelve of the 15 anti-HBc positive donors were anti-HBs positive and three anti-HBs negative (Table 2).

On examination of the PHLS special panel, all but one $\mathrm{HBsAg}$ positive sample, No 6 , were anti-HBc positive by RIA. This sample, which had the lowest HBsAg activity in the BPL-RIA test and was RPHA negative, was slightly reactive in the anti-HBc assay (Table 4).

Seventy-four donations which had initially given an anti-HBc positive reaction on CIE screening were retested by RIA. None of the 19 giving unconfirmable CIE reactions was positive in the RIA test for anti-HBc, whereas all but two of the 53 confirmable CIE reactions were. There were no other markers of HBV infection in the two sera with discrepant results.

\section{Discussion}

The prevalence of anti-HBc in new blood donors, measured by both CIE and by RIA, was $0.7 \%$. In a selected group of donors, those previously screened at this centre, the prevalence was lower, $0.4 \%$, whereas in prisoner donors anti-HBc was much more common (3.4\%). An increased occurrence of HBV infection in penal institutions has previously been reported. ${ }^{10}$ The prevalence of anti-HBc in blood donors was less than half that in another British survey of new donors. Tedder and colleagues ${ }^{11}$ apparently found $37(1.85 \%)$ out of 2000 North London donors anti-HBc positive. Since the RIA used by them is known to be of similar sensitivity to that employed here, the difference probably reflects the more cosmopolitan background and varied sociosexual habits of Londoners, and not a difference between the assays.

The results for the panels of control sera confirmed that the anti-HBc test was effective in identifying $\mathrm{HBsAg}$ positive specimens. All but two 
of the panel of $139 \mathrm{HBsAg}$ positive sera, as well as the $\mathrm{HBs} \mathrm{Ag}$ positive donors, were anti-HBc positive by CIE. The two negative anti-HBc results were on specimens with very low levels of HBsAg. Four other HBsAg weakly positive specimens, in the PHLS special panel, were missed by the CIE test for anti-HBc. When RIA for anti-HBc was applied to the special panel one HBsAg specimen was not clearly identified, though it did partially inhibit ${ }^{125} \mathrm{I}-$ anti-HBc binding. These results do not justify using anti-HBc testing alone to screen blood donations, but they indicate that it can usually confirm HBsAg positivity in donors. Only blood collected in the incubation period of $\mathrm{HBV}$ infection is likely to be $\mathrm{HBsAg}$ positive but anti-HBc negative.

As well as identifying more weak $\mathrm{HBsAg}$ positive specimens, RIA for anti-HBc proved to be more specific than CIE. It gave negative results for all the 19 donors whose sera produced unconfirmable reactions on initial CIE screening. It gave only three positive reactions, out of 2586 donors tested, that were not corroborated by a positive anti-HBs result. These three may have been false-positive reactions or they may belong in a true "anti-HBc only" category. The eight donor sera that were "anti-HBc only" when tested by CIE may fit into the same category. Donor blood with this pattern of reactivity has given rise to both type $B$ and non-A, non-B posttransfusion hepatitis. ${ }^{12-14}$ It is therefore undesirable that it should be transfused.

The donations found by us to be anti-HBc positive were dealt with as follows: those known to be HBsAg positive were discarded; those anti-HBs positive were sent for inclusion in pools for the production of HBV immune globulin (HBIG); and those in the "anti-HBc only" category were set aside for possible use in blood product manufacture involving processes that inactivate $\mathrm{HBV}$. In our donor population the prevalence of anti-HBc was low enough for all anti-HBc positive blood to be withheld from transfusion. As most anti-HBs positive donations also have anti-HBc (Tedder and coworkers $^{11}$ found 27 with and 15 without anti-HBc in 2000 donors) considerably fewer donations with any marker of HBV infection can have been transfused while anti-HBc screening was being applied.

A striking advantage of the anti-HBc test was its rapidity. Both methods described give a result within two hours, and allow quick confirmation of HBsAg screening results and fast release of urgently required fresh blood and blood constituents. This may be particularly useful in providing for those needing multiple transfusions-for example, renal dialysis and immunosuppressed patients. The main disadvantage of anti-HBc testing was the high incidence of apparently non-specific reactions. Many results could not be reproduced in the more experienced, reference laboratory. Another drawback at the time of the study was the short supply of antigen, though this obstacle has now been overcome by the cloning of HBV DNA sequences in $E$ coli. ${ }^{15} E$ coliderived $\mathrm{HBcAg}$ is suitable for an RIA of the kind used here ${ }^{16}$ and may give rise to fewer false-positive reactions.

Other disincentives to anti-HBc screening are the potential loss of transfusable blood, and the cost, both of the test itself and of anti-HBs tests that must be done if anti-HBc positive, $\mathrm{HBsAg}$ negative units are to be used. These factors will certainly prevent anti-HBc tests being used by poorly-funded laboratories in areas of high prevalence. Elsewhere the benefits from anti-HBc testing, of confirming $\mathrm{HBs} \mathrm{Ag}$ reactions, of identifying donations suitable for HBIG manufacture and of lessening the risk of post-transfusion hepatitis by excluding "anti-HBc only" blood, ought to be studied. Several authors have argued that an anti-HBc test is not useful in blood donor screening, ${ }^{11217}$ They cite the small number of cases of post-transfusion hepatitis due to anti-HBc positive units brought to the notice of transfusion centres. However they ignore the larger numbers of sub-clinical infections, with $\mathrm{HBV}$ and possibly non-A, non-B hepatitis viruses, that may follow transfusion of anti-HBc positive blood. They also overlook several practical advantages of having an anti-HBc test available in transfusion laboratories. In the form of a rapid, one-step RIA the test is well-suited to screening large batches of sera. With an abundant supply of $\mathrm{HBcAg}$ from $E$ coli becoming available, it should be reconsidered as an adjunct to $\mathrm{HBsAg}$ screening of blood donors.

We thank Mr RA Hewish for technical assistance, Dr EM Vandervelde and Mrs JY Mortimer for advice, and Miss B Mandalia for secretarial help.

\section{References}

' Hoofnagle JH, Gerety RJ, Ni LY, Barker LF. Antibody to hepatitis B core antigen: a sensitive indicator of hepatitis B virus replication. $N$ Engl J Med 1974;290:1136-40.

${ }^{2}$ Lander JT, Gitnick GL, Gelb LH, Aach RD. Anti-core antibody screening of transfused blood. Vox Sang 1978;34:77-80.

${ }^{3}$ Hoofnagle JH, Seeff LB, Bales ZB, Simmerman HJ, and the Veterans Administrative hepatitis co-operative study. Type B hepatitis after transfusion with blood containing antibody to hepatitis B core antigen. N Engl J Med 1978;298:1379-83.

4 Katchaki JN, Siem TH, Brouwer R. Serological evidence of presence of $\mathrm{HBsAg}$ undetectable by conventional radioimmunoassay in anti-HBc positive blood donors. J Clin Pathol 1978;31:837-9.

${ }^{5}$ Wilkinson R. The impact of anti-HBc screening on a Black blood donor population. S Afr J Med Lab Technol 1982;28:9-11.

- Cohen BJ, Cossart YE. Application of a screening test for antibody to hepatitis B core antigen. J Clin Pathol 1977;30:70913. 
' Archer AC. An improved haemagglutination technique for detection of hepatitis Bs antigen. Med Lab Sci 1977;34:34550.

- Cohen BJ, Mortimer PP, Hewish RD. Comparison of radioimmunoassay and counter-immunoelectrophoresis for the detection of antibody to hepatitis B core antigen. $J$ Virol Methods 1981;2:181-92.

9 Cameron CH, Combridge BS, Howell DR, Barbara JAJ. A sensitive immunoradiometric assay for the detection of hepatitis B surface antigen. $J$ Virol Methods 1980;1:311-23.

${ }^{10}$ Chiaramonte M, Trivello R, Renzulli G, et al. Hepatitis B virus infection in prisons. A seroepidemiological survey in prisoners and attending staff. J Hyg Camb 1982;89:53-8.

"Tedder RS, Cameron CH, Wilson-Croome R, Howell DR, Colgrove A, Barbara JAJ. Contrasting patterns and frequency of antibodies to the Surface, core, and e antigens of hepatitis B virus in blood donor, and in homosexual patients. J Med Virol 1980;6:323-32.

${ }^{12}$ Hopkins R, Kane E, Robertson AE, Haase G. Hepatitis B virus transmitted by $\mathrm{HBsAg}$ negative blood containing anti-HBc. Med Lab Sci 1982;39:61-2.

${ }^{13}$ Cossart YE, Kirsch S, Ismay SL. Post-transfusion hepatitis in
Australia: report of the Australian Red Cross Study. Lancet 1982;i:208-13.

${ }^{14}$ Stevens CE and the Transfusion-Transmitted Viruses Study Group. Antibody to hepatitis B core antigen in donor blood and the risk of non A non B hepatitis in recipients. Transfusion 1981;21:607.

${ }^{15}$ Burrell CJ, MacKay P, Greenaway PJ, Hofschneider PH, Murray $\mathrm{K}$. Expression in Escherichia coli of hepatitis B virus DNA sequences cloned in plasmid pBR322. Nature 1979;279:43-7.

${ }^{16}$ Peutherer JF, MacKay P, Ross R, Stahl S, Murray K. Use of the hepatitis B core antigen produced in Escherichia coli in an assay for anti-HBc. Med Lab Sci 1981;38:355-8.

17 Dike AE. Post-transfusion hepatitis B transmitted by HBsAg negative blood containing anti-HBc. Med Lab Sci 1981;38:415-7.

Requests for reprints to: Dr PP Mortimer, PHLS Virus Reference Laboratory, Central Public Health Laboratory, Colindale Avenue, London NW9 5HT, England. 